\title{
Localization of Glycine and Beta-Adrenergic Receptors in the Rat Brain
}

\author{
Masaya Tohyama, Akio Wanaka, Toshiyuki Araki ${ }^{1}$, Heinrich BetZ ${ }^{2}$ and Caig C. Malbon ${ }^{3}$ \\ Department of Anatomy ${ }^{1}$, Osaka University Medical School, Osaka, Japan; Zentrum für Molekulare Biologie ${ }^{2}$, Universität \\ Heidelberg, Heidelberg, F. R. G. and Department of Pharmacological Sciences ${ }^{3}$, State University of New York at Stony Brook, \\ New York, U. S. A.
}

\begin{abstract}
Summary. The localization of glycine (GR) and adrenergic receptors (AdR) was examined in the rat brain using a monoclonal antibody against the affinity purified glycine receptor and a polyclonal antibody against purified beta b $_{2}-$ AdR. GR were concentrated in the lower brainstem, whereas no immunoreactivity was observed in the diencephalon and forebrain except in a few diencephalic nuclei. The highest density was found in the cranial motor nuclei, reticular formation, parabrachial area, dorsal and ventral cochlear nuclei, and dorsal and ventral tegmental nuclei. On the other hand, AdR were widely but unevenly distributed in the rat brain. The present study further showed the presence of AdR in catecholaminergic terminals in the hypothalamus.
\end{abstract}

The localization of glycine and catecholamine (CA) in the brain have been examined morphologically by various methods. In addition, the binding to their receptors has been examined by autoradiography. Recent advances in molecular biology and biochemical techniques have made it possible to explore the molecular profiles of receptors (BETZ et al., 1983; BenOvic et al., 1984; PfEiffer et al., 1984; Moxham and MALBON, 1985; BeTZ, 1987; KoBILKA et al., 1987; MALBON et al., 1987). In the present study, we employed antisera against purified glycine and beta $_{2}$ adrenergic receptors to examine immunohistochemically the precise location of these receptors in the rat brain.

\section{MATERIALS AND METHODS}

\section{Preparation of tissues}

Sixteen male adult albino rats each weighing about $100 \mathrm{~g}$ (eight animals for analysis for the glycine receptors and the remaining for beta $_{2}$-adrenergic receptors) were used. The animals were perfused intracar- dially with $50 \mathrm{ml}$ of ice-cold saline followed by $300 \mathrm{ml}$ of ice-cold $4 \%$ paraformaldehyde in $0.01 \mathrm{M}$ phosphate buffer ( $\mathrm{pH}$ 7.4). The brain was removed rapidly, put it in the same fixative for $24 \mathrm{~h}$ at $4^{\circ} \mathrm{C}$, and rinsed in phosphate buffered saline (PBS) containing 30\% sucrose for $24 \mathrm{~h}$ at $4^{\circ} \mathrm{C}$. Frozen sections $(10 \mu \mathrm{m}$ thick $)$ were cut along the frontal plane on a cryostat and mounted on chrome-alum gelatin coated slides.

\section{Immunocytochemical procedure}

The sections were divided into two groups, one for the detection of cells and fibers with glycine receptors (GR) or beta-adrenergic receptors (beta-AdR)-like immunoreactivity and the other for the identification of regions of the brain by cresyl violet staining. Some of the samples of the first group were subjected to absorption tests to determine the specificity of the antisera.

\section{Preparation and characterization of the antisera}

Antiserum against GR : GR have been solibulized and purified by affinity chromatography on immunostrychnine agarose. This preparation contains three polypeptides with molecular weights of $48,000,58,000$ and 93,000 (BETZ et al., 1983; PFEIFFER et al., 1984; BETZ, 1987). The monoclonal antibody GlyR $7 \mathrm{a}$ specific for the 93,000 mol. wt. subunit of the GR was used in this study. Characterization of this antiserum has been reported elsewhere (PFEIFFER et al., 1984; BETZ, 1987; TRILlER et al., 1987).

Antiserum against beta ${ }_{2}-A d R$ : Beta $_{2}$-AdR was purified by affinity chromatography and ion-exchange chromatography from the guinea pig lung in $0.1 \mathrm{ml}$ of $200 \mathrm{mM} \mathrm{NaCl}$ containing $100 \mathrm{mM} \mathrm{KH}_{2} \mathrm{HPO}_{4}(\mathrm{pH} \mathrm{7.4)}$ and $0.05 \%$ digitonin. New Zealand white rabbits were immunized with $3 \mu \mathrm{g}$ of purified beta $\mathrm{a}_{2}$-AdR coupled with the myeloma cells as an antigen. The antibody titer was checked by solid-phase enzyme-linked immunosorbent assay (ELISA) (MoxHAM et al., 1986). 
The overall predicted structures of G-protein coupled receptors such as alpha ${ }_{1}$, alpha ${ }_{2}$, beta ${ }_{1}$, beta ${ }_{2}$-AdR, and rhodopsin receptors are homologous (DOHLMAN et al., 1987; KoBILKA et al., 1987; MALBON et al., 1987). Therefore, when the cross-reactivity of anti beta ${ }_{2}-A d R$ antiserum with beta ${ }_{1}-A d R$ of rat adipose cells was tested by immunoprecipitation, between $60 \%$ and $84 \%$ of beta $_{1}$-AdR was immunoprecipitated (MoxhAm et al., 1986). The antiserum used in this study thus appears to recognize both beta $_{1}$ - and beta $_{2}-A d R$. The cross-reactivity with the rhodopsin receptor of the antiserum used in this study was considered to be low, because no immunostaining was seen in the outer segment or outer nuclear layer of the retina, which contains many rhodopsin receptors. In the cranial motor nuclei, immunostaining was slight to relatively moderate compared with the high density of quinuxlidinyl benzilate binding sites (WAM . SLEY et al., 1981), suggesting that there was little or no cross-reactivity of the antiserum with muscarinic cholinergic receptors. The possibility that the antiserum cross-reacted with dopamine receptors seems slight, because no immunostaining was noted in the striatum where the density of $\left[{ }^{3} \mathrm{H}\right]$ spirperone binding was high (PALACIOS et al., 1981). Areas containing a high density of $\left[{ }^{3} \mathrm{H}\right]$ clonidine binding sites such as the nuclei of the solitary tract, locus coeruleus, and lateral parabrachial nucleus displayed high levels
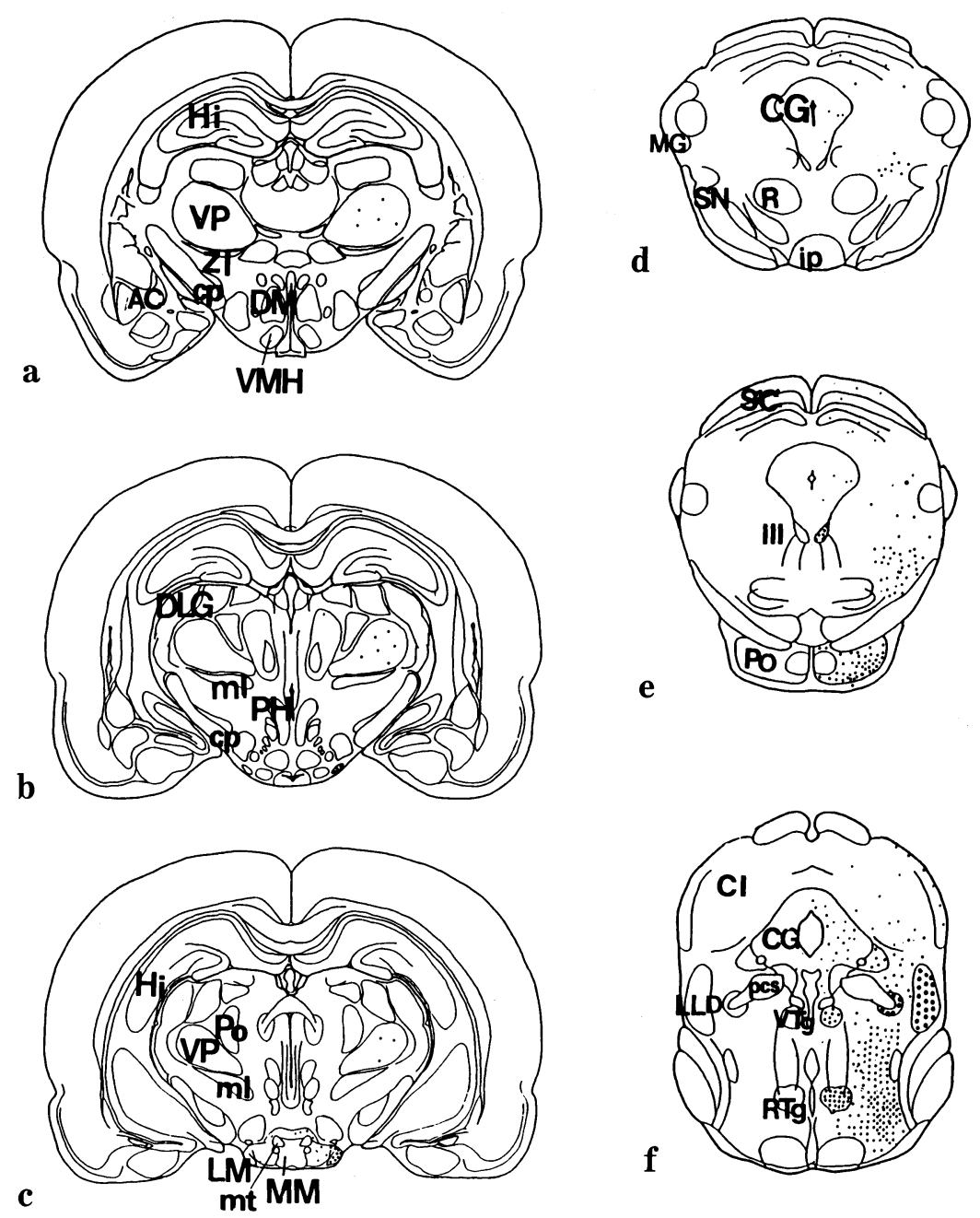

Fig. 1 a-l. Schematic drawing of the distribution of GR in the rat brain. Frontal plane arranged from rostral to caudal. Large dots indicate GR concentrated on the surface of the soma, and small dots that are distributed evenly in the neuropil. Reproduced from ARAKI et al. (1988). 
of immunoreactivity (UNNERSTALL et al., 1984). A rich plexus in the thalamus, which was strongly and specifically labeled with $\left.{ }^{125} \mathrm{I}\right]$ [2-beta-(4-hydroxyphenyl)-ethylaminomethyl-tetralone] (JoNEs et al., 1985a, b), did not exhibit immunoreactivity. Thus, the antiserum has little cross-reactivity with alpha ${ }_{1}-A d R$, but may cross-react to some extent with alpha $a_{2}$-AdR.

The likehood of crossreaction occurring between the antiserum used in this study and alpha ${ }_{2}-A d R$ or dopamine receptor was examined in additional control experiments. The antiserum employed in this study had previously been shown to inhibit the binding of ligands (MoXHAM et al., 1986). We therefore examined whether or not the immunoreaction was displaced with an excess amount of ligands. Details are as follows: anti beta ${ }_{2}$-AdR antiserum was diluted with buffers containing either $1 \mathrm{mM}$ alprenolol, $1 \mathrm{mM}$ clonidine, or $1 \mathrm{mM}$ spiperone. Sections were preincubated with one of these solutions before being examined immunocytochemistry. Immunostaining was markedly reduced when the sections were in cubated with the solution containing alprenolol. However, no reduction of the immunoreaction was seen in the sections incubated with the solution containing clonidine or spiperone. These findings strongly suggest that the antiserum against beta ${ }_{2}$ AdR used in these experiments recongized both subtypes of beta-AdR but had little cross-reactivity with alpha 2 -AdR or dopamine receptor.
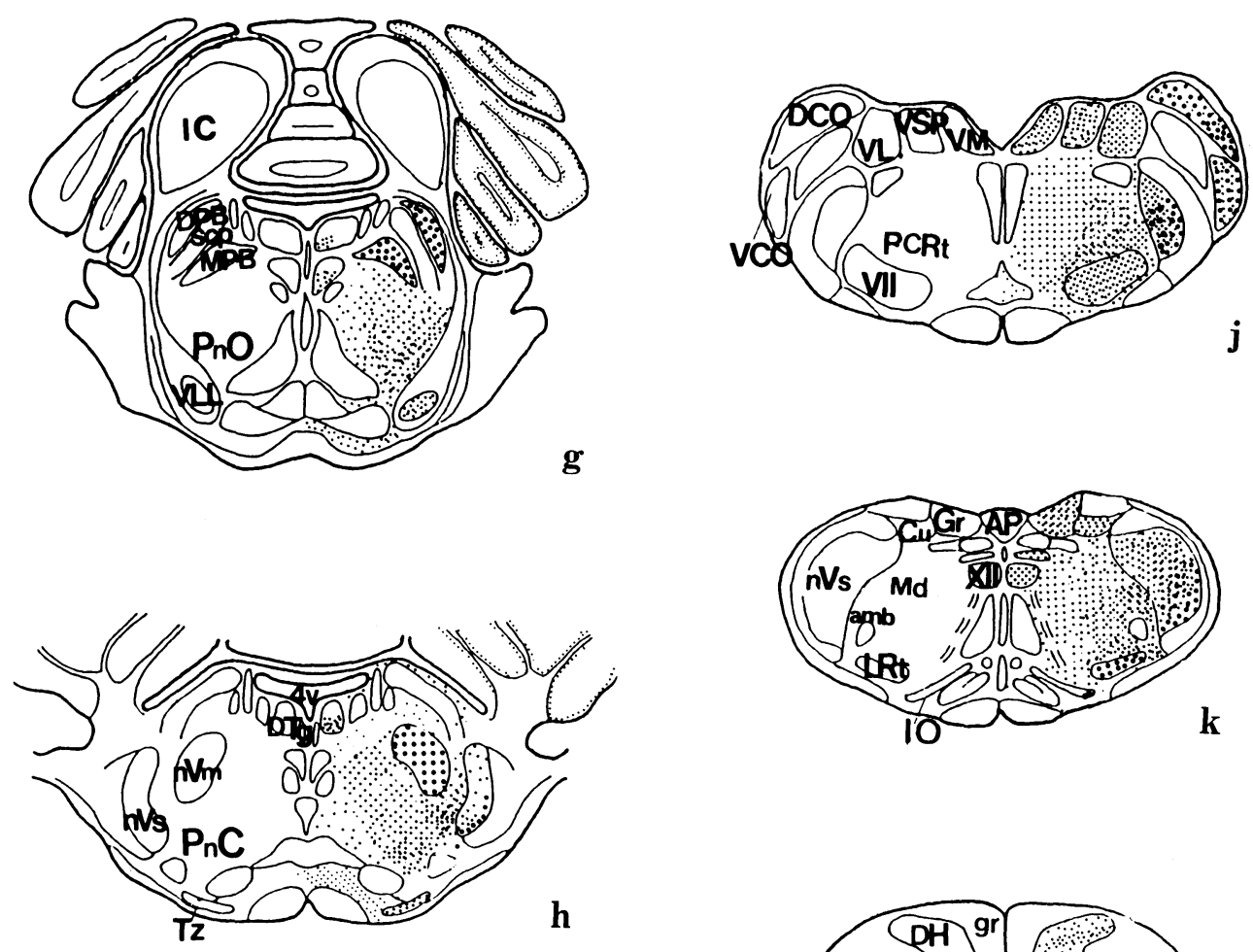

Fig. $1 \mathrm{~g}-\mathbf{l}$.
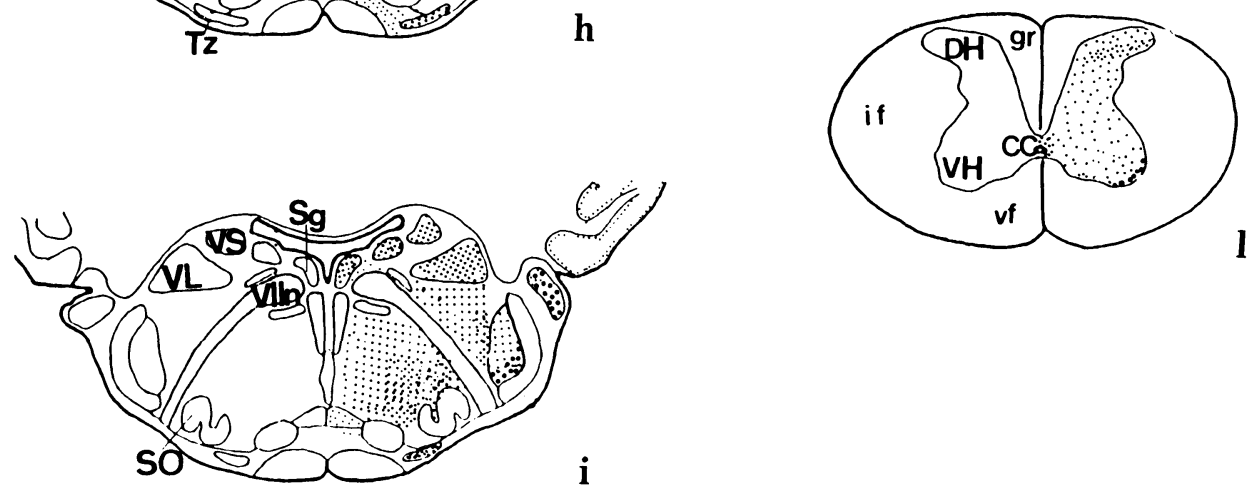


\section{RESULTS AND DISCUSSION}

\section{Localization of the GR}

Our immunocytochemical study indicated that the GR-immunoreactive structures were widely but unevenly distributed in the brain and spinal cord. They were localized on the surface of the neuronal elements in both continuous and discontinuous patterns. The immunostaining was generally punctated and concentrated on the surface of the soma.

Our results are summarized in Figure 1. Few GR-immunoreactive structures were deteceted in the forebrain and diencephalon except in a few diencephalic nuclei such as the lateral mammillary nucleus. In the thalamus, a few immunoreactive structures were found only in the posteroventral thalamic nucleus. In the hypothalamus, immunoreactivity was only seen in the mammillary and postmammillary regions. On the other hand, the lower brainstem and spinal cord were very rich in GR-immunoreactive structures. The highest density of the receptors was found in the cranial motor nuclei, reticular formation, parabrachial area, dorsal and ventral cochlear nuclei (Fig. 2), and dorsal and ventral tegmental nucleus. Differences were observed in the various brain regions. In the cerebellar cortex, the immunoreactivity was exclusively seen along the dendrites of the Purkinje cells. On the other hand, GR-immuno- reactivity was detected on the cellular membrane of the soma of the cochlear nuclei (Fig. 2), trigeminal motor nucleus, parabrachial area, lateral reticular nucleus, anterior horn and reticular formation. In other regions, the receptors were evenly distributed throughout the neuropil.

Figure 3 is an electronmicrograph showing the fine structure of the GR-immunoreactivity in the dorsal cochlear nucleus. Immunoreaction was restricted at the postsynaptic density.

\section{Localization of the beta-AdR}

Beta-AdR was widely but unevenly distributed in a punctate pattern throughout the brain. The distribution of beta-AdR in the brain is presented schematically in Figure 4. Beta-AdR was found mainly on the surface of the neurons, on the proximal parts of their processes, or within the cytoplasm (Fig. 5D-F), although the intensity of the immunoreaction differed among the regions of the brain. In some instances, the receptors had a varicose fiber-like appearance (Fig. $5 \mathrm{~A}, \mathrm{~B}$ ) or were distributed in the neuropil as fine dots (Fig. 5C).

In the forebrain and diencephalon, cells with betaAdR were abundant in the cerebral cortex, hippocampus, and various hypothalamic nuclei other than the ventromedial hypothalamic nucleus and the suprachiasmatic nucleus. Few or no cells with betaAdR were found in the thalamus except in the lateral
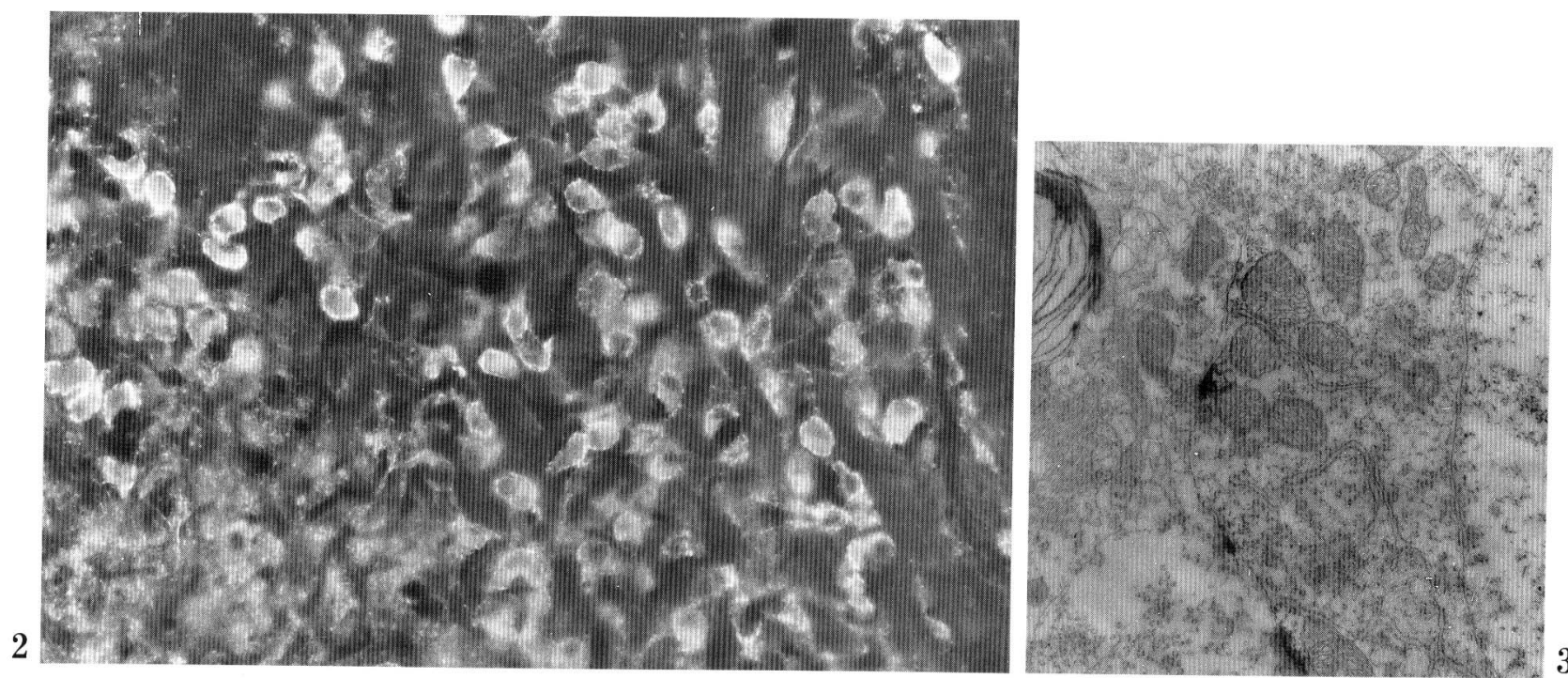

Fig. 2. Fluorescence photomicrograph showing GR-immunoreactivity in the dorsal cochlear nucleus. Note that the immunoreactive structures are concentrated on the surface of the neurons of this nucleus. Frontal plane. Reproduced from ARAKI et al. (1988).

Fig. 3. Electron photomicrograph showing GR-immunoreactivity in the dorsal cochlear nucleus. Note the immunoreaction products associated only with the postsynaptic density. 

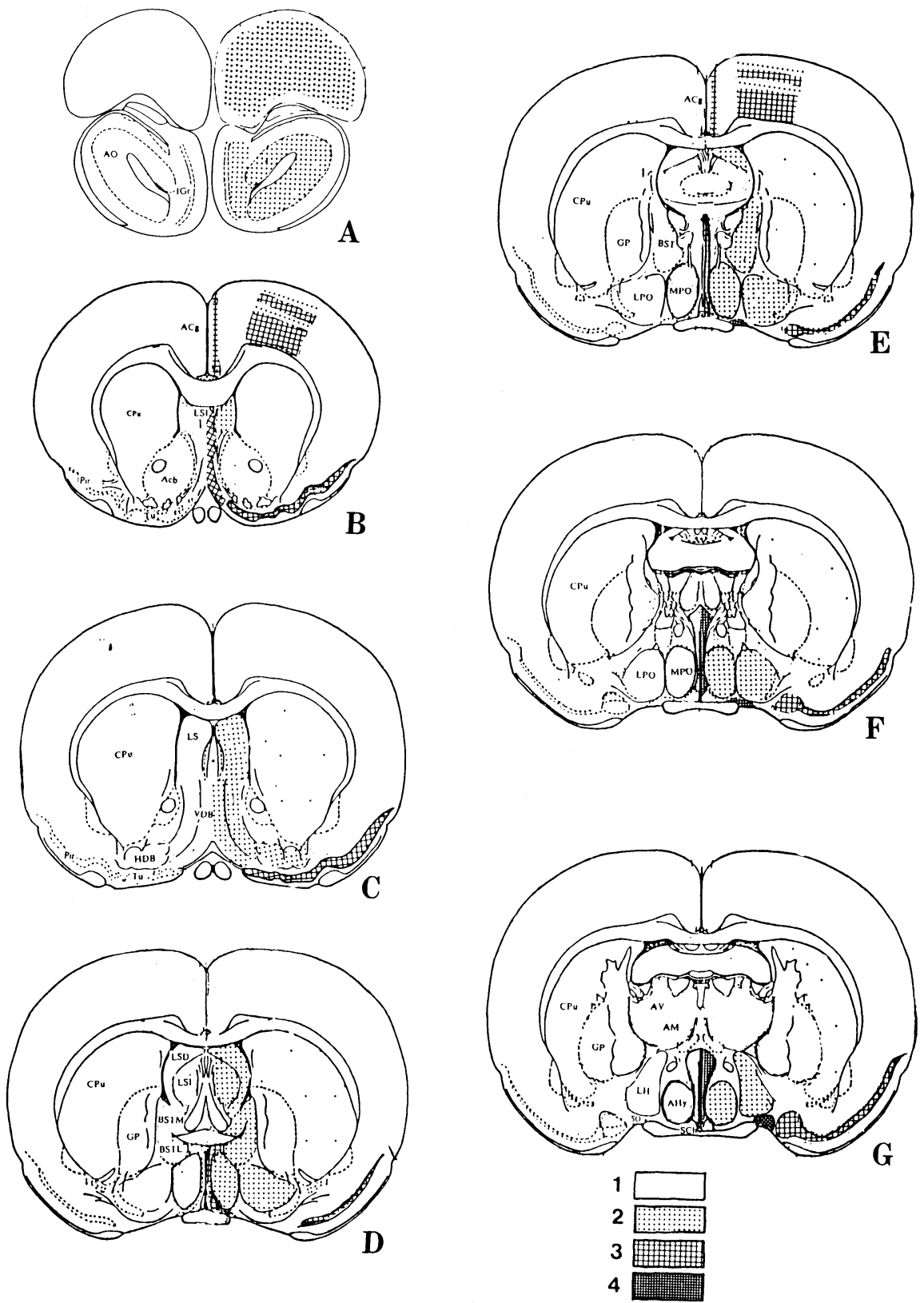

Fig. 4 A-U. Schematic representation of the distribution of beta-AdR in the rat brain. The frontal plane is arranged rostrally to caudally. The hatching (1-4; see the key at the bottom of Fig. 4G) in the right half of each drawing indicates the intensity of staining of neurons with 1 being weak, 2 being weak to moderate, 3 being moderate to strong and 4 being strong. The distribution of beta-AdR in the cerebral cortex was closely similar to that seen in the rostrocaudal area and is presented in B, E, H, L. Reproduced from WANAKA et al. (1989a). 


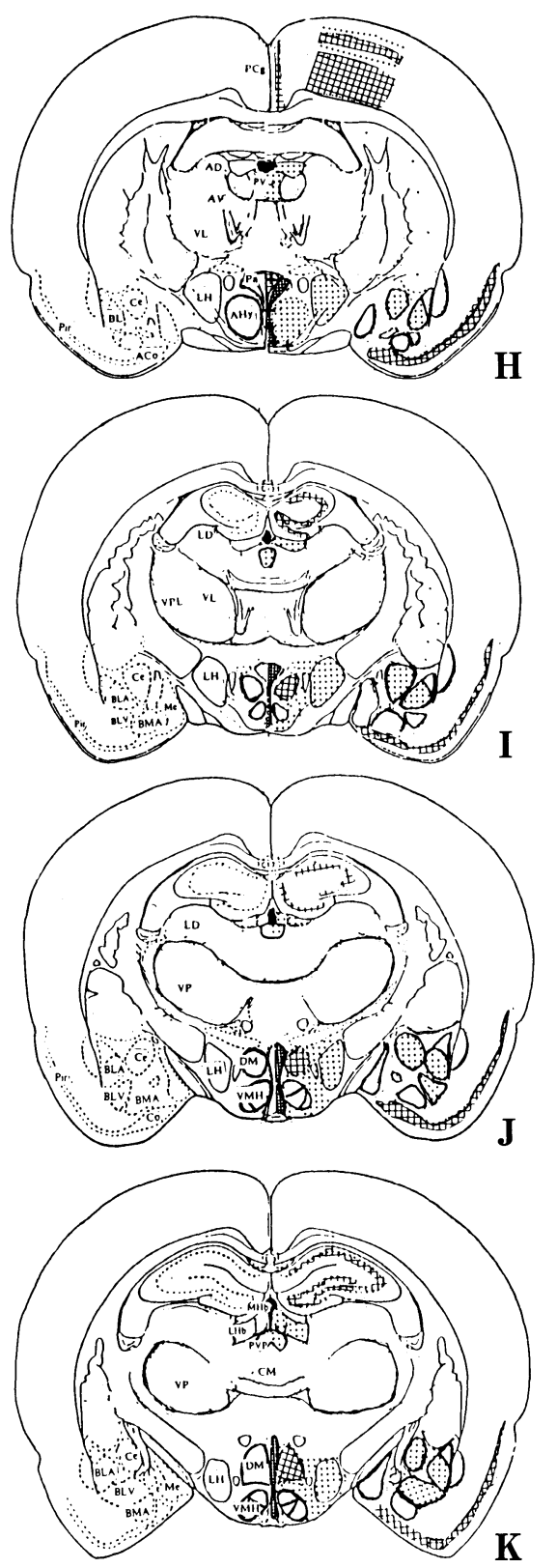

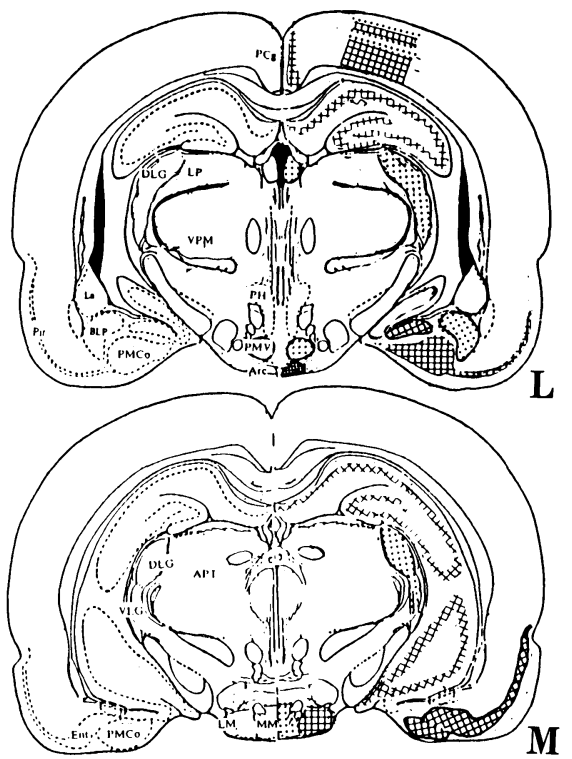
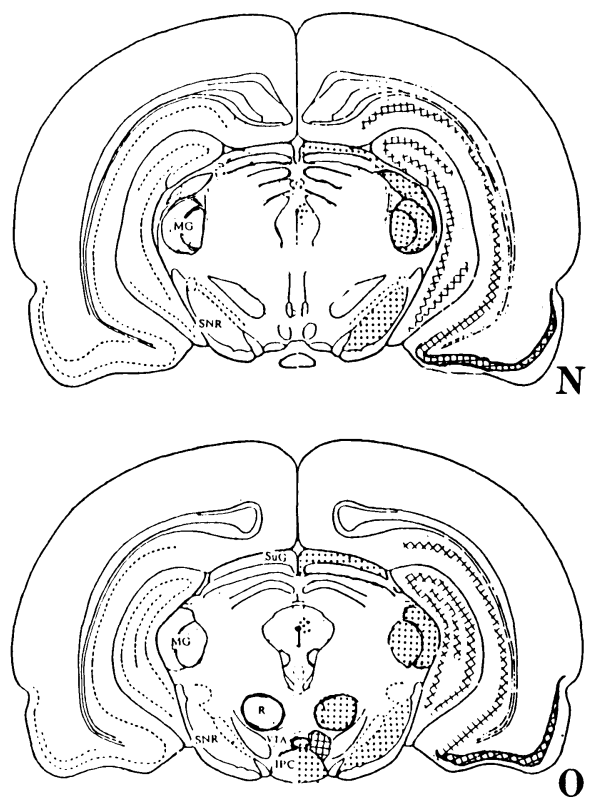

Fig. $4 \mathrm{H}-\mathrm{O}$.

Legend on p. 43 and medial geniculate nucleus, habenular nuclei and paraventricular thalamic nucleus. The striatum, globus pallidus, and accumbens nucleus also contained few beta-AdR. In the lower brainstem, the nucleus of the solitary tract, parabrachial area, the areas related to the auditory system such as inferior colliculus, the nucleus of the lateral lemniscus and the cochlear nuclei, and the areas related to the cerebellar function such as the reticulotegmental nucleus of the pons, the pontine nuclei, the lateral reticular nucleus and the inferior olive, were all rich in beta-
AdR.

As described above, there were a number of immunoreactive fibers with punctate profiles in the periventricular zone of the hypothalamus, and a few which were varicose in appearance like axonal fibers. Furthermore, other inveatigators have shown by pharmacological means that the beta-AdR is localized in the presynaptic catecholaminergic fibers (ADLER-GRASCHINSKY and LANGER, 1975; LANGER, 1987). Therefore, we tried to elucidate immunocytochemically whether or not the varicose fibers labeled 

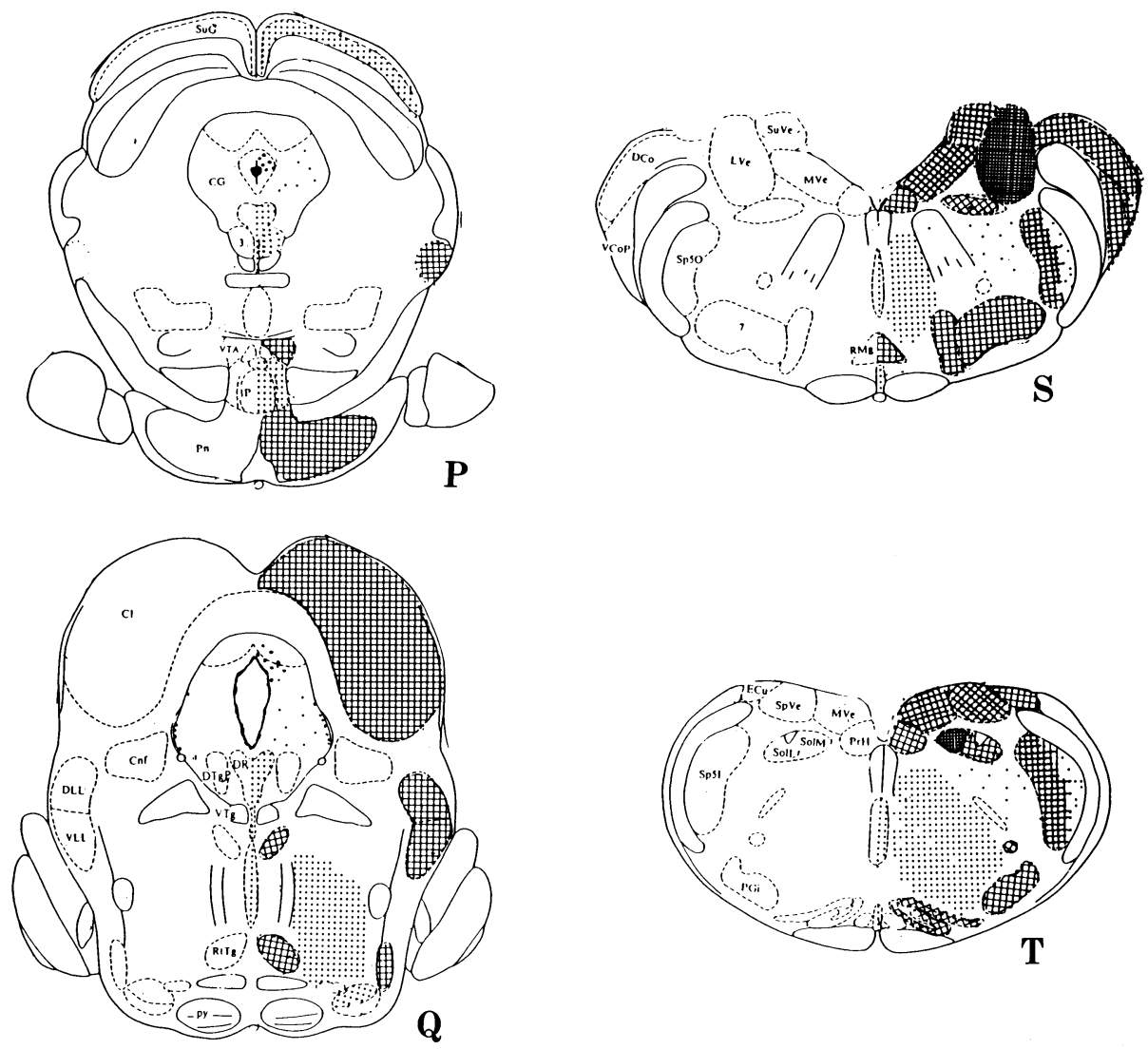

Fig. 4 P-U. Legend on p. 43.

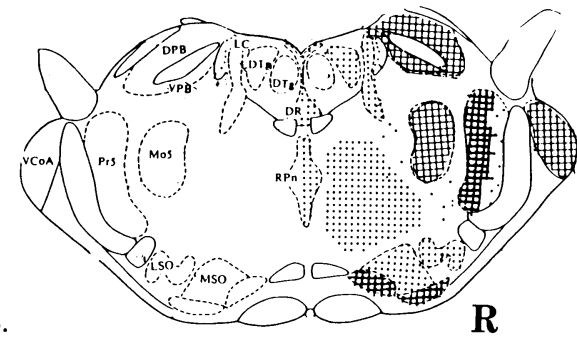

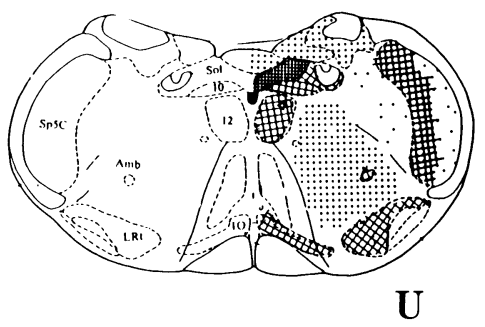

by the anti-beta-AdR antiserum are catecholaminergic axons in the periventricular zone of the rat hypothalamus. Tyrosine hydroxylase (TH) was used as a marker for catecholaminergic systems.

Figure 6 (left half) shows the fibers with beta-AdRimmunoreactivity in the periventricular zone of the hypothalamus. The localization of the TH-immunoreactivity in the same area is presented in the right half of Figure 6. Many of the latter fibers and neurons lacked beta-AdR-Immunoreactivity, while the betaAdR-immunoreactivity fibers shown in the left half of
Figure 6 (arrowheads) displayed concurrent THimmunoreactivity. In Figure 7, the ultrastructure of the beta-AdR-Immunoreactivity fibers from Figure 6 is shown. The labeled fibers were filled with synaptic vesicles, indicating that they were axon terminals. Immunoreactive end-products were mainly associated with these synaptic vesicles, and sometimes with either cellular or mitochondrial surface membrane. However, careful survey of the fine structures of beta-AdR fibers and neurons indicated that the above mentioned profiles were not very frequent, and most 
of the beta-AdR-immunoreactivity occurred in the dendrites or in the soma. In these structures, immunoreactive end-products were associated with the postsynaptic densities where non-labeled terminals arrived; they were also found scattered in the dendroplasm and cytoplasm, some of which were associated with the endoplasmic reticulum. Thus, the present study clearly demonstrated that catecholaminergic axon terminals contain beta-AdR, strongly suggesting that this beta-AdR belongs to a presynaptic autoreceptor.

A
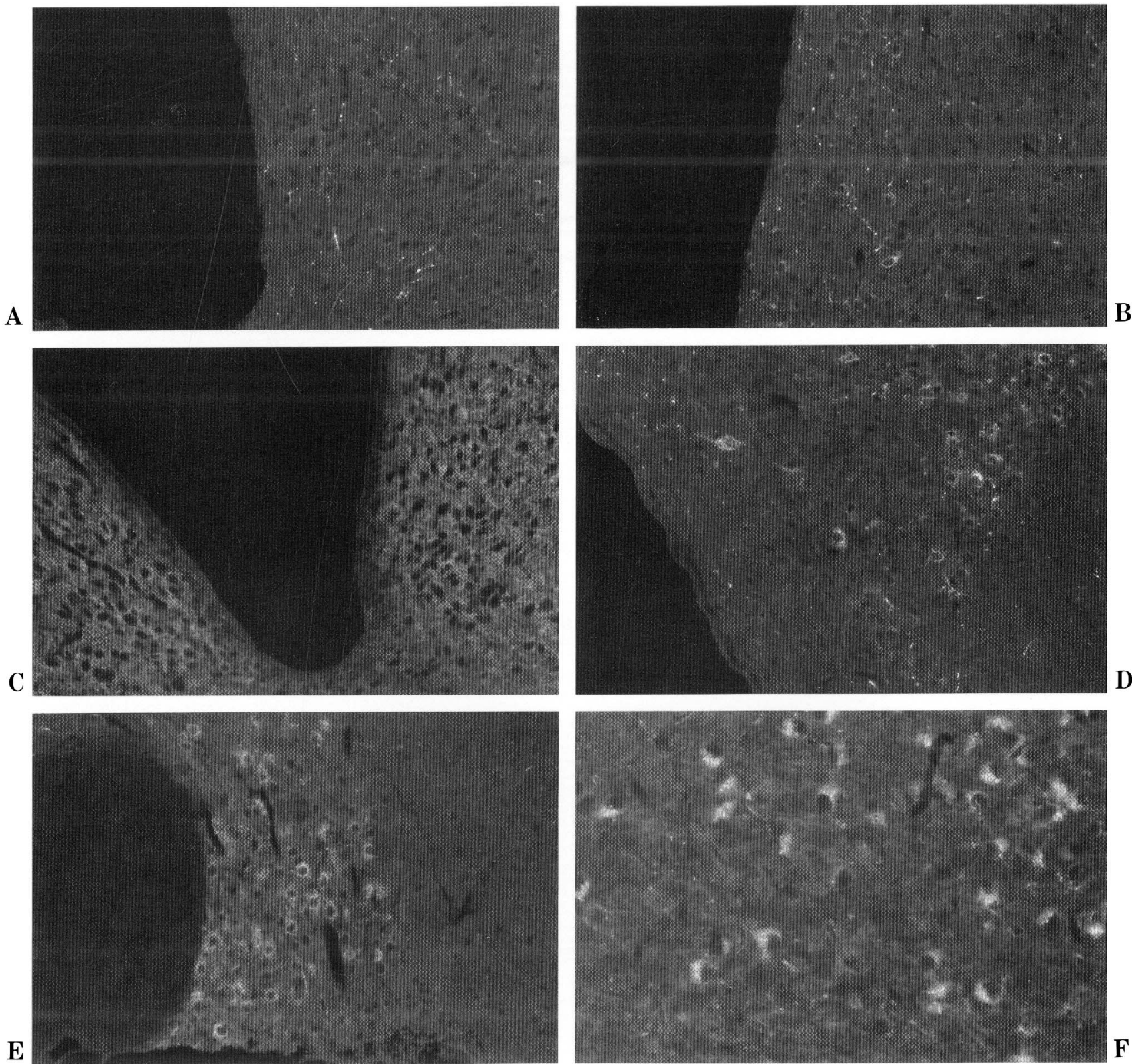

Fig. 5 A-F. Fluorescence photomicrographs showing beta-AdR containing fibers in the periventricular zone of the preoptic area $(\mathbf{A})$, and dorsal $(\mathbf{B})$ and ventral $(\mathbf{C})$ parts of the periventricular zone of the hypothalamus. Note the high concentration of fibers with beta-AdR in the ventral part of the periventricular $z o n e(\mathbf{C})$. D-F. Fluorescence photomicrographs showing cells with beta-AdR in the paraventricular nucleus (D), suparoptic nucleus (E) and medial mammillary nucleus (F). Frontal sections. Reproduced from WANAKA et al. (1989a). 

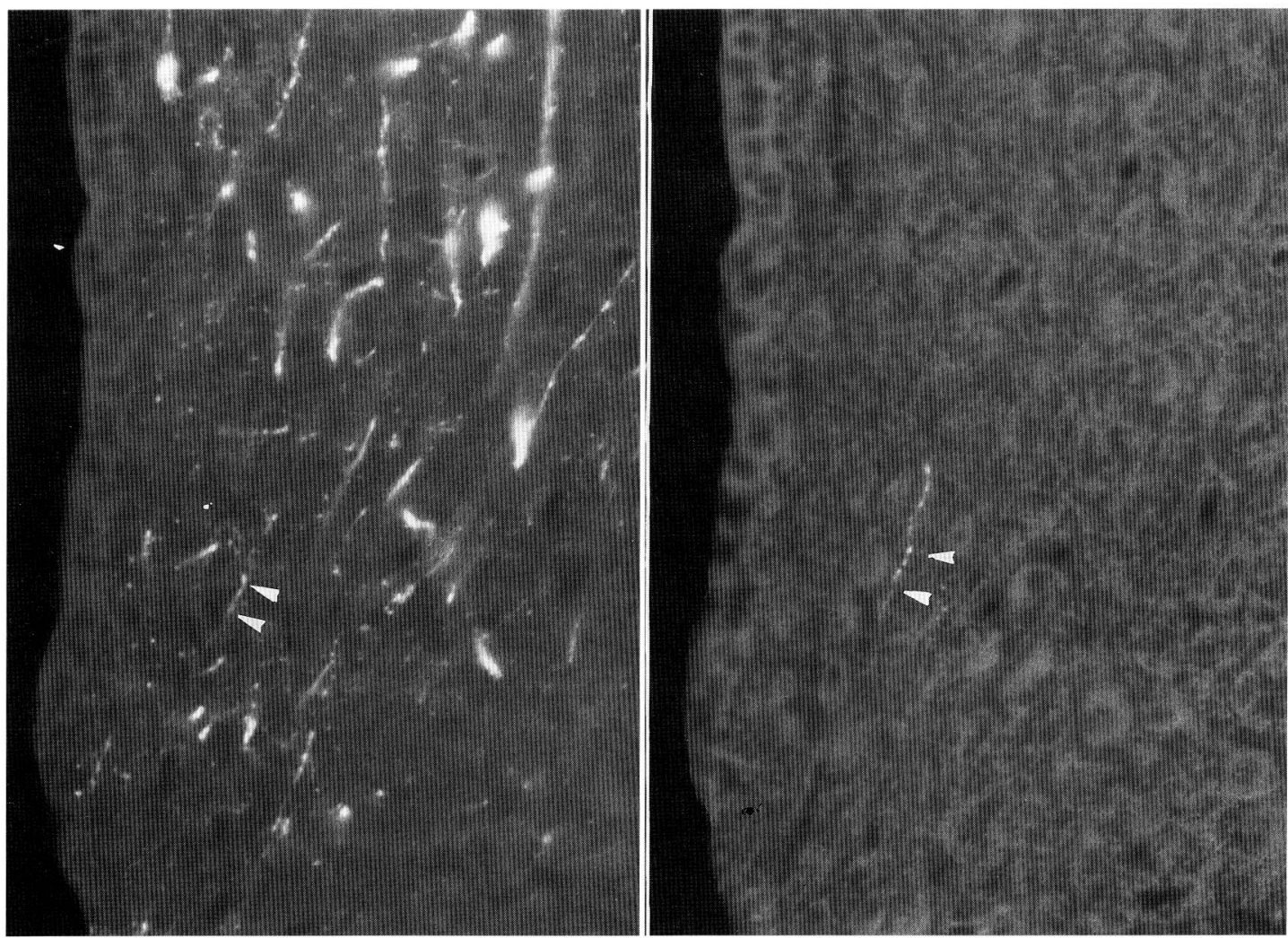

Fig. 6. Fluorescence photomicrographs of a double labeled section of the hypothalamic periventricular zone (left half; beta-AdR-immunoreactivity, right half; TH-immunoreactivity). Note that the running patterns of both types of immunoreactive fiber (arrowheads) are closely similar. Frontal section. Reproduced from WANAKA et al. (1989b).

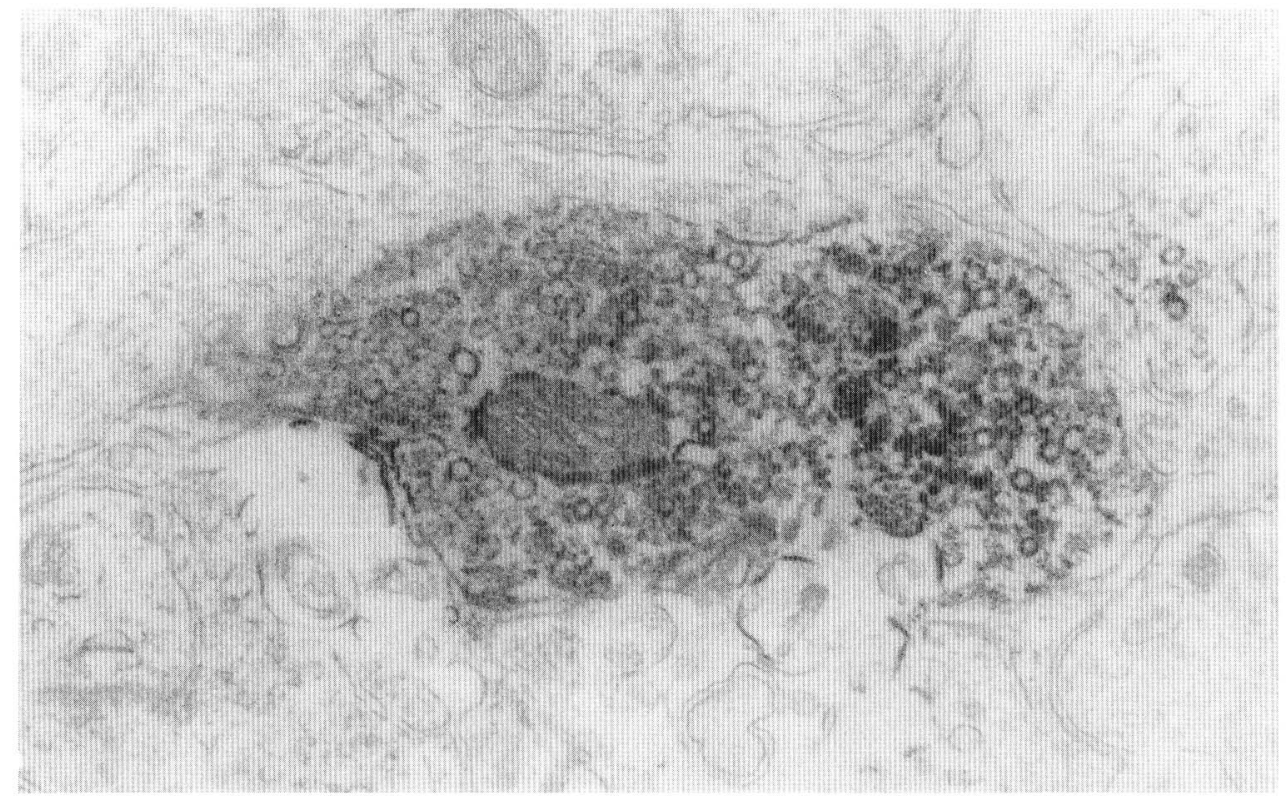

Fig. 7. Electron photomicrograph of a beta-AdR-immunoreactivity immunoreactive fiber (presented in Fig. 6). Note the numerous synaptic vesicles. Reproduced from WANAKA et al. (1989b). 


\section{REFERENCES}

Adler-Graschinsky, E. and S. Z. Langer: Possible role of a beta-adrenoreceptor in the regulation of noradrenaline release by nerve stimulation through a positive feed-back mechanism. Brit. J. Pharmacol. 53: 43-50 (1975).

Araki, T., M. Yamano, T. Murakami, A. Wanaka, H. BETZ and M. TohYAMA: Localization of glycine receptors in the rat central nervous system: an immunocytochemical analysis using monoclonal antibody. Neuroscience 25: 613-624 (1988).

Benovic, J. L., R. G. L. ShorR, M. G. Caron and R. J. LEFKowITZ: The mammalian beta ${ }_{2}$-adrenergic receptor: Purification and characterization. Biochemistry 23 : 4510-4518 (1984).

BETZ, H.: Biology and structure of the mammalian glycine receptor. Trends. Neurosci. 10: 113-117 (1987).

Betz, H., D. Graham, F. Pffeiffer and H. Reham : Alpha-bungarotoxin and strychinine as tools to characterize neurotransmitter receptors of the central nervous system. In: (ed. by) F. Hucho and Y. A. Ovchinikov: Toxins as tools in neurochemistry. Gruyter, Berlin, 1983 (p. 245-255).

Dohlman, H. G., M. G. Caron and R. J. Lefkowitz: A family of receptors coupled to guanine nucleotide regulatory proteins. Biochemistry 26: 2657-2664 (1987).

JoNes, L. S., L. L. GAUger and J. N. Davis: Anatomy of brain alpha-1-adrenergic receptors: In vitro autoradiography with [ $\left.{ }^{125} \mathrm{I}\right]$-HEAT. J. Comp. Neurol. 231: 190-208 (1985a).

Jones, L. S., L. L. Gauger, J. N. Davis, T. A. Slotkin and J. V. BALtolome: Postnatal development of brain alpha-1-adrenergic receptors: In vitro autoradiography with $\left[{ }^{125} \mathrm{I}\right]$-HEAT in normal rats treated with alphadifluoromethylornithine, a specific, irreversible inhibitor of ornithine decarboxylase. Neuroscience 15: 1195-1202 (1985b).

Kobilka, B. K., T. Frielle, S. Collins, T. YANG-Feng, T. S. Kobilka, U. Francke, R. J. LeFKowitz and M. G. CARON: An intornless gene encoding a potential member of the family of receptors coupled to guanine nucleotide reguratory proteins. Nature 329: 75-79 (1987).

LANGER, S. Z.: Presynaptic regulation of monoaminergic neurons. In: (ed. by) H. Y. MELTZER: Psychopharmacology. Raven Press, New York, 1987 (p. 151-157).

Malbon, C. C., S. T. George and C. P. MoxhaM: Intramolecular disulfide bridges: avenues to receptor activation. TIBS 12: 172-175 (1987).
Moxham, C. P., S. T. George, M. P. Graziano, H. J. BRANDWEIN and C. C. MAlbon: Mammalian beta ${ }_{1}$ and beta $_{2}$-adrenergic receptors. Immunological and structural comparisons. J. Biol. Chem. 261: 14562-14570 (1986).

Moxham, C. P. and C. C. Malbon: Fat cell beta - $^{-}$ adrenergic receptor: structural evidence for existence of disulfide bridge for ligand binding. Biochemistry 24 : 6072-6077 (1985)

Palacios, J. M., D. L. Niehoff and M. J. Kuhar: $\left[{ }^{3} \mathrm{H}\right]$ spiperone binding sites in brain: autoradiographic localization of receptors. Brain Res. 213: 277-289 (1981).

Pfeiffer, A., R. Simeler, G. Grenningloh and $\mathbf{H}$. NETZ: Monoclonal antibodies and peptides mapping reveal structural similarities between the subunit of the glycine receptors of rat spinal cord. Proc. Nat. Acad. Sci. USA. 81: 7224-7227 (1984).

Triller, A., F. Cluzeaud and H. Korn: Gammaaminobutyric acid containing terminals can be apposed to glycine receptor at central synapses. J. Cell Biol. 104 : 947-956 (1987).

Unnerstall, J. R., T. A. Kopajtic and M. J. Kuhar: Distribution of alpha $_{2}$-agonist binding sites in the rat and human central nervous system: Analysis of some functional, anatomic correlates of the pharmacologic effects of clonidine and related adrenergic agents. Brain Res. Rev. 7: 69-101 (1984).

W AMSley, J. K., M. S. LeWIS, W. M. Young, III. and M. J. KUHAR: Autoradiographic localization of muscarinic receptors in rat brain stem. J. Neurosci. 1: 176-191 (1981)

W ANAKA, A., H. KiYAMA, T. MURAKami, M. Matsumoto, T. Kamada, C. C. Malbon and M. Tohyama: Immunocytochemical localization of beta-adrenergic receptors in the rat brain. Brain Res. $485: 125-140$ (1989a).

W anaka, A., C. C. Malbon, M. Matsumoto and M. Tohyama: Presence of catecholaminergic axon terminals containing beta-adrenergic receptor in the periventricular zone of the rat hypothalamus. Brain Res. 479 : 190-193 (1989b).
Prof. Masaya ToHyama Department of Anatomy II Osaka University Medical School 4-3-57 Nakanoshima, Kita-ku Osaka, 530 Japan 